\title{
A OUTRA FACE DA RESPONSABILIDADE SOCIAL EMPRESARIAL A LUZ DAS CIÊNCIAS SOCIAIS APLICADAS: A ATUAÇÃO DO ASSISTENTE SOCIAL EM FOCO
}

\author{
Gisele Dayane Milani
}

Pontifícia Universidade Católica de São Paulo - PUC. Mestranda do Programa de Pós - Graduação em Serviço Social, São Paulo - SP. E-mail: giselemilani@hotmail.com

\section{RESUMO}

No âmbito acadêmico, discussão sobre a responsabilidade social encontra-se presente na área da Administração como uma nova forma de gestão dos negócios, bem como nas Ciências Sociais Aplicadas em que inclui-se o Serviço Social no que concerne seu objeto de trabalho. O meio empresarial é um espaço contraditório e que demanda do profissional de Serviço Social atender o empresariado e os sujeitos que recebem as ações, sempre pautando sua ação pelo Projeto Ético Político, que dá a direção social do agir profissional. No que tange aos desafios e possibilidades do trabalho do Assistente Social em ações de Responsabilidade Social, foi possível compreender que os maiores desafios concernem ao campo das contradições em ir além dos objetivos corporativos no atendimento das exigências do empresariado e das demandas dos sujeitos. Como possibilidades, verificou-se que há espaços na gestão das ações, na articulação de redes e parcerias.

Palavras-chave: Responsabilidade Social Empresarial. Desafios e Possibilidades. Serviço Social.

\section{OTHER FACE OF CORPORATE SOCIAL RESPONSIBILITY IN THE APPLIED SOCIAL SCIENCES: THE PRACTICE OF THE SOCIAL WORKER IN FOCUS}

\begin{abstract}
In the academic environment, discussion of social responsibility is present in the Administration area as a new form of business management, as well as the Social Sciences which includes the Social Work regarding your work object. The corporate environment is a contradictory space and demand for social work to attend the business and the individuals who receive actions, always basing their action for the Ethical Political Project, which gives the social direction of professional acting professional. In relation to the challenges and opportunities of the Social Worker working in Social Responsibility actions, it was possible to understand that the greatest challenges concern the place of contradictions go beyond business in compliance with the requirements of the business and the demands. As possibilities, it was found that there are gaps in the management of actions, the articulation of networks and partnerships.
\end{abstract}

Keywords: Corporate Social Responsibility. Challenges and Possibilities. Social Work. 


\section{INTRODUÇÃO}

Este artigo é resultado de uma pesquisa de Mestrado em andamento cujo objeto de pesquisa concerne a temática da Responsabilidade Social empresarial e o Serviço Social. Teve por objetivo discutir a emergência e evolução da Responsabilidade Social, bem como suas novas configurações e Serviço Social na empresa, especificamente envolvido em ações socialmente responsáveis. Este tema tem relevância social e acadêmica por ser um tema atual que transcende a área da Administração e abre espaços nas Ciências Sociais aplicadas. O objeto desse trabalho são os desafios e as possibilidades de atuação do Assistente Social frente à Responsabilidade Social Empresarial. Foi problematizado o surgimento da Responsabilidade Social e a adesão do Serviço Social à sua prática.

Esta é uma pesquisa bibliográfica que abrangeu o estudo e análise de referenciais teóricos acerca da Responsabilidade Social. A metodologia utilizada contemplou as pesquisas bibliográfica e eletrônica. Foi utilizado o método Dialético, pois se sustenta em um processo contínuo de mudanças e tudo é considerado como um complexo de processos que estão sempre em constante transformação.

Os Assistentes Sociais foram chamados para intervir nessa nova demanda - as ações de Responsabilidade Social - o que exigiu do profissional a busca por novos conhecimentos acerca do tema e novas metodologias de trabalho, uma vez que, tudo que é novo é desafiador. Entre tais mudanças no campo sócio- ocupacional do Assistente Social, foram destacados os limites institucionais e as possibilidades que o profissional encontra nesse meio.

\section{OS DESAFIOS E AS POSSIBILIDADES DA ATUAÇÃO DO ASSISTENTE SOCIAL FRENTE À RESPONSABILIDADE SOCIAL EMPRESARIAL}

O objetivo deste item foi de elaborar reflexões para aprofundar o debate sobre a inserção e atuação do Assistente Social no universo empresarial, assim como analisar os desafios e possibilidades que rodeiam seu cotidiano profissional nas ações de Responsabilidade Social.

De acordo com Lima (2005, p. 237), desde 1940 algumas empresas já dispunham de Assistentes Sociais no seu quadro de funcionários. No entanto, somente no final da década de 1970 e início da década de 1980, foi que se verificou um significativo aumento de profissionais de Serviço Social no ramo empresarial, em razão da flexibilização dos processos de produção que repercutiram, principalmente, na sociedade e nas relações de trabalho. 
Inicialmente, a intervenção do Assistente Social nas empresas esteve voltada para a gestão dos recursos humanos, programas participativos, e educativos, qualidade de vida do trabalhador, voluntariado e etc. Como afirma Mota (1991, p. 16):

[...] a presença do assistente social na empresa, antes de qualquer coisa, vem confirmar que a expansão do capital implica na criação de novas necessidades sociais. Isto é, a empresa, enquanto representação institucional do capital, passa a requisitar o assistente social para desenvolver um trabalho de cunho assistencial e educativo junto ao empregado e sua família.

Conforme citação, por meio do trabalho do Assistente Social a empresa almejava controlar e disciplinar a força de trabalho, ao mesmo tempo em que aumentava os níveis de produção. Desse modo, o profissional atendia às necessidades do trabalhador e sua família de acordo com as requisições do capital. É assim que também o afirma lamamoto (2008, p. 47):

O Serviço Social sempre foi chamado pelas empresas para eliminar focos de tensões sociais, criar um comportamento produtivo da força de trabalho, contribuindo para reduzir o absenteísmo, viabilizar benefícios sociais, atuar em relações humanas na esfera do trabalho.

Assim, ressalta-se que a requisição deste profissional pelas empresas, de modo geral, confirma o surgimento de novas demandas sociais no âmbito empresarial para desenvolver um trabalho que imprime, principalmente, um cunho educativo e assistencial para com o empregado, sua família e dependentes. As empresas notaram que o Assistente Social poderia contribuir na organização das relações pessoais que perpassam no âmbito laboral. Isso porque buscavam proporcionar ganhos em termos de qualidade de vida no trabalho, que na verdade estavam reafirmando os interesses capitalistas da instituição empregadora.

Em meio às ações de Responsabilidade Social que as empresas passaram a desenvolver, os Assistentes Sociais foram chamados para intervir nessas novas demandas que surgiram no mundo da produção o que exigiu do profissional a busca por novos conhecimentos acerca do tema e novas metodologias de trabalho, pois tudo que é novo é desafiador.

Sob esse prisma, a atuação dos Assistentes Sociais junto às organizações empresariais, face o crescente investimento das empresas na Responsabilidade Social, pode ser um diferencial nas práticas socialmente responsáveis. O que está em questão, no entanto, é o novo modelo de gestão empresarial que envolve as relações da empresa com seus diversos públicos, em um campo de contradições que merece ênfase sob um olhar crítico. 
O exercício profissional é permeado de possibilidades, desempenhado por meio da socialização de informações alusivas aos direitos sociais, da atuação em benefícios sociais e da articulação de redes e parcerias. A ação profissional pode se expressar também, através de assessorias para a formulação, coordenação e gestão de projetos sociais.

O Assistente Social não deve, simplesmente, se moldar aos cronogramas institucionais, mas, por outro lado, não pode negar as atividades e os objetivos da instituição no processo de reelaboração do objeto, que tem início na "operacionalização das demandas institucionais [...] a demanda institucional é o ponto de partida" (BAPTISTA, 2010, p. 32). Entende-se, portanto, que este é um desafio, mas que a ação não se esgota nos reclames do empresariado, devendo o profissional se apropriar de novas metodologias de trabalho, sendo criativo e estratégico.

Para Menezes (2010, p. 525), o profissional:

[...] não deve também nutrir ilusões quanto à possibilidade de as práticas sociais das empresas serem a solução para o pauperismo em que se encontra grande parcela da população e nem deve se enganar, acreditando que o mercado está comprometido realmente com a superação da desigualdade social.

Conforme citação acima, as ações sociais das empresas não se configuram efetivamente como solução para as demandas, muito menos o mercado possui esse intuito. O que se efetiva são práticas assistencialistas, pontuais, que visam o consenso entre as classes e a diminuição dos espaços de participação e reivindicação dos sujeitos.

Convém destacar que o Projeto Ético Político é composto pela Lei no 8.662/93, que regulamenta a profissão de Serviço Social, o Código de Ética de 1993 e as Diretrizes Curriculares para os cursos de Serviço Social. Este projeto dá direcionamento ao agir profissional. O Projeto Ético Político do Serviço Social tem uma estrutura básica, dialeticamente compreendida em três dimensões: ética, política e profissional. Essas dimensões fazem parte dos valores do Projeto da Profissão e essa estrutura não deve ser compreendida como três dimensões separadas, mas devem ser dialeticamente compreendidas, pois estão interligadas.

Cabe ressaltar que é necessário ao Assistente Social inserido nas ações de responsabilidade social a busca constante pelo conhecimento. E, ainda que ele não seja apenas um executor de ações que lhe são impostas, mas que crie novas ações dentro de seus limites e possibilidades institucionais, pautadas no Projeto Ético Político Profissional da categoria. É importante ainda, que o profissional elabore processos de participação e de conscientização com o intuito de desenvolver uma consciência 
crítica nos trabalhadores ou sujeitos atendidos pelas ações de Responsabilidade Social, ultrapassando apenas o interesse individual e possibilitando a participação deste nas decisões no que se refere às suas necessidades.

Nessa perspectiva, possibilidades são postas ao Assistente Social que deve desenvolver seu potencial estrategista e articulador. Ainda mais por estar inserido em uma dinâmica contraditória que se constituem, por um lado pelas exigências da organização contratante, e por outro pelas necessidades dos trabalhadores ou usuários. O desafio, no entanto, constitui-se na capacidade em atender ambos e superar essa contradição.

A fim de melhor esclarecer os desafios e possibilidades do trabalho do Assistente Social em ações de Responsabilidade Social, segue abaixo o Quadro 3, explicativo sobre os desafios e possibilidades. Cabe mencionar que o quadro é uma produção das autoras, realizado através de reflexões durante as orientações e com base nos textos estudados nesse tópico dos autores: Baptista (2010, p. 32), Menegasso (2001, p. 69) e lamamoto (2008, p. 47).

Quadro 1. Desafios e Possibilidades

\begin{tabular}{|c|c|}
\hline Desafios & Possibilidades \\
\hline $\begin{array}{l}\text { - Mudanças do cotidiano } \\
\text { impulsionadas pela instituição } \\
\text { empregadora, pela economia e } \\
\text { pelo sistema de produção; } \\
\text { - Intervir nessas novas demandas } \\
\text { que surgiram no mundo da } \\
\text { produção; } \\
\text { - Campo contraditório; } \\
\text { - Ir além dos objetivos corporativos } \\
\text { e estratégias empresariais } \\
\text { requisitados; } \\
\text { Capacidade de atender às } \\
\text { exigências da organização } \\
\text { contratante e aos requerimentos } \\
\text { dos trabalhadores ou usuários e } \\
\text { superar essa contradição; } \\
\text { Criar metodologias qualificadas } \\
\text { para dar respostas às requisições } \\
\text { do meio empresarial. }\end{array}$ & $\begin{array}{l}\text { - Socialização de informações } \\
\text { alusivas aos direitos sociais; } \\
\text { - Articulação de redes e parcerias; } \\
\text { - Efetivar a gestão nas dimensões } \\
\text { propositiva, executiva e avaliativa; } \\
\text { - Posicionamento teórico- } \\
\text { metodológico, ético-político e } \\
\text { técnico-operativo para } \\
\text { desenvolver o trabalho } \\
\text { profissional considerando os } \\
\text { limites institucionais e buscando } \\
\text { superá-los; } \\
\text { - Possibilidade de fazer a leitura do } \\
\text { objeto sobre o qual que vai } \\
\text { intervir; } \\
\text { - Trabalho interdisciplinar. }\end{array}$ \\
\hline
\end{tabular}

Fonte: Baptista (2010, p. 32), Menegasso (2001, p. 69) e lamamoto (2008, p. 47). Quadro elaborado pela autora. 
Entende-se que a inserção do Serviço Social no meio empresarial está permeada por interesses contraditórios, - não que em outros campos estes não existam - mas este, especificamente, é um campo sócio ocupacional desafiador, na medida em que o profissional é contratado pelo empresariado para garantir os objetivos corporativos e estratégias empresariais. Entende-se que é contraditório consolidar espaços democráticos no campo do mercado, pois este possui uma lógica de lucratividade e compreende-se que cabe ao Estado a tarefa de intervir no que concerne às demandas da área social, pois é do Estado a função de provedor de direitos sociais.

Embora o Assistente Social esteja inserido em um espaço contraditório e os princípios que segue sejam diferentes dos interesses empresariais, entende-se que nos limites e desafios do cotidiano é possível viabilizar possibilidades e frentes de trabalho efetivando o Projeto da profissão. 0 pressuposto desta afirmação é que quando o profissional intervém nas expressões da questão social, sua prática expressa um posicionamento ao mesmo tempo teórico metodológico, ético político e técnico operativo, orientado por princípios e valores defendidos pela categoria profissional.

A atualidade suscita repensar valores que regem a vida em sociedade, em uma perspectiva voltada ao desenvolvimento social e econômico sustentável. Aos poucos, o Serviço Social vem aumentando cada vez mais as discussões críticas a respeito da Responsabilidade Social das Empresas. Foi possível notar pelos estudos teóricos, que o trabalho do Assistente Social em ações de Responsabilidade Social está repleto de desafios, em um campo contraditório, mas foi possível notar ainda que nele existem possibilidades intrínsecas a serem viabilizadas.

\section{CONSIDERAÇÕES FINAIS}

Esse Trabalho teve como finalidade suscitar reflexões acerca da inserção do Assistente Social na empresa, especificamente em ações socialmente responsáveis. Verificou-se que o que impulsionou o empresariado a adotar um comportamento socialmente responsável no trato com a gestão dos negócios está mais além da contribuição para uma sociedade mais justa ou da busca da sustentabilidade. O que remete ao entendimento de que a outra face da Responsabilidade Social está permeada de interesses privados, comerciais e de âmbito econômico, que trazem como principais vantagens a melhora da imagem institucional e a valorização da marca.

O meio empresarial é um espaço contraditório para as ações de Responsabilidade Social e que demanda do profissional de Serviço Social atender o empresariado e os sujeitos que recebem as ações, sempre pautando sua ação pelo Projeto Ético Político, que dá a direção social do agir 
profissional. Conforme foi exposto o ideário dos Assistentes Sociais fundamenta-se na defesa dos direitos sociais, da justiça social, dos direitos humanos, da liberdade, da emancipação, entre outros, defendidos pela categoria profissional e que simbolizam a direção social que a intervenção do profissional deve buscar.

No que tange aos desafios e possibilidades do trabalho do Assistente Social em ações de Responsabilidade Social, foi possível compreender que os maiores desafios concernem ao campo das contradições em ir além dos objetivos corporativos no atendimento das exigências do empresariado e das demandas dos sujeitos. Como possibilidades, verificou-se que há espaços na gestão das ações, na articulação de redes e parcerias e embora o Assistente Social esteja inserido em um espaço contraditório e os princípios que este segue sejam distintos dos objetivos empresariais, entende-se que nos limites e desafios institucionais é possível viabilizar possibilidades e frentes de trabalho efetivando o Projeto da profissão.

Verificou-se que não é obrigatório para as empresas terem o Assistente Social envolvido nas ações de Responsabilidade Social. No entanto, entende-se ser de suma importância a atuação desse profissional em tais ações, pois possui um olhar crítico, capacidade não apenas de executor, mas também de investigar e intervir na realidade social.

Por fim, a partir o exposto foi possível notar que o Serviço Social vem ampliando as discussões em relação ao tema em tela e que essa pesquisa comtemplou esforços na construção de uma reflexão sobre as ações de Responsabilidade social e o assistente social nesse espaço sócio ocupacional.

\section{REFERENCIAS}

BATISTA, Myrian Veras. Planejamento Social: intencionalidade e instrumentação. 2 ed. São Paulo. Veras; Lisbora: CPIHTS; 2010.

BRASIL. Lei que regulamenta a Profissão de Serviço Social. Lei n 8.662, de 7 de junho de 1993. Brasília, DF, Senado, 1993.

CFESS. Conselho Federal de Assistentes Sociais. Código de ética profissional do assistente social. Brasília: Conselho Federal de Assistentes Sociais, 1993.

CRESS. Conselho Regional de Serviço Social 17ạ Região. Projeto Ético-Político. Disponível em: <http://cress-es.org.br/projetoetico.htm>. Acesso: 15 ago. 2012.

IAMAMOTO, Marilda Villela. O serviço social na contemporaneidade: trabalho e formação profissional. 16. ed. São Paulo: Cortez, 2008. 
LIMA, Maria José de Oliveira. Serviço Social na Empresa. Revista Katálysis b.8 .2 jul./dez. 2005 Florianópolis SC 235-246. Disponível em:

<http://www.periodicos.ufsc.br/index.php/katalysis/article/view/6116/5679>. Acesso: 08 ago. 2012.

MENEGASSO, Ester Maria. Responsabilidade Social das empresas: um desafio para o Serviço Social. Revista Katálysis n. 5/2001 Estado, sociedade civil e democracia. Disponível em:

<http://www.periodicos.ufsc.br/index.php/katalysis/article/view/5724>. Acesso: 08 jul. 2012.

MENEZES, Franciane Cristina de. Serviço Social e a "responsabilidade social das empresas": o debate da categoria profissional na Revista Serviço Social \& Sociedade e nos CBAS. In: SERVICO Social \& Sociedade. São Paulo: Cortez 2010. N 103.

MOTA, Ana Elizabete da. O feitiço da ajuda: as determinações do serviço social na empresa. 3. ed. São Paulo: Cortez, 1991.

NETTO, José Paulo. A Construção do Projeto Ético-Político do Serviço Social. Disponível em: <http://www.fnepas.org.br/pdf/servico_social_saude/texto2-1.pdf>. Acesso: 28 ago. 2012. 